\title{
Pamukkale Üniversitesi Hastanesi Kardiyoloji Polikliniğine başvuran hipertansiyon hastalarında polifarmasi ve etkileyen faktörler
}

\author{
Polypharmacy and affecting factors in hypertension patients who admitted to Pamukkale \\ University Hospital Cardiology outpatient clinic
}

\author{
Özgür Sevinç, Mehmet Koray Adalı, Ayşen Til, Yeşim Kınacı Çimen
}

Gönderilme tarihi:26.03.2018

Kabul tarihi:09.11.2018

\begin{abstract}
Özet
Amaç: Epidemiyolojik dönüşüm sonucunda bulaşıcı hastalıklardan bulaşıcı olmayan hastalıklara geçişin yaşandığı birçok gelişmekte olan ülkede hipertansiyon önemli bir halk sağlığı sorunu olarak kabul edilmektedir. Gelişmiş ve gelişmekte olan ülkelerde farklılık göstermekle birlikte hipertansiyon prevalansı \%25-55 arasında bulunmaktadır. Ayrıca hipertansiyon hastaları polifarmasi açısından risk grupları arasında yer almaktadır. Polifarmasi, hasta uyumunun azalmasına, ilaç-ilaç etkileşimine, yanlış ilaç kullanımına, istenmeyen ilaç yan etkilerine yol açmakta ve acil servis başvurularında ve hastaneye yatışlarda artışa neden olduğu için tüm dünyada önemli bir sağlık sorunu olarak değerlendirilmektedir.

Çalışmamızda PAÜ hastanesi kardiyoloji polikliniğine başvuran hipertansiyon hastalarının polifarmasi durumları ve etkileyen faktörlerin belirlenmesi amaçlanmıştır.

Yöntem ve Gereçler: Kesitsel tipteki araştırmamıza 320 hipertansiyon hastası katılmıştır. Çalışmaya katılan hastalara, tıp yazını taranarak oluşturulan 21 soruluk bir anket formu uygulanmıştır. Tedavi uyumları Morisky Tedavi Uyum Ölçeği (MTUÖ-8) kullanılarak ölçülmüştür.

Veriler SPSS 17 programıyla analiz edilmiş olup tanımlayıcı istatistikler, sınıflandırılmış değişkenler için sayı ve yüzdeler verilmiştir. Yüzdeler arasındaki farklar ise Ki-kare testi ile test edilmiştir. Ortalamalar arasındaki farklar için Mann Whitney U testi kullanılmıştır. Anlamlılık düzeyi 0,05 olarak kabul edilmiştir.

Bulgular: Araştırmaya katılan kişilerin 153'ü $(\% 47,8)$ kadındır, 249'u $(\% 78,3)$ evlidir. Yaş ortancası 63 yıldır. Günlük dört ve daha fazla ilaç kullanım oranı tüm grupta $\% 54,4(n=174)$, günlük beş ve daha fazla ilaç kullanım oranı tüm grupta \%44,4 ( $n=142)$ olarak bulunmuştur. Katılımcıların \%49,5'inin $(n=141)$ tedaviye uyumu kötüdür. Yaş, cinsiyet, öğrenim durumu, riskli davranış varlığı, ek kronik hastalık varlığı, hipertansiyon hastalık süresi, sigara kullanımı ve tedavi uyumu değişkenlerinden oluşan regresyon modelinde, düşük eğitim seviyesi (OR=5,67, $\mathrm{GA}=3,26-9,86)$, ek kronik hastalığın olması $(\mathrm{OR}=2,02, \mathrm{GA}=1,11-3,69)$, ve uzun süredir hipertansiyon hastası olmak (OR=2,91, GA=1,61-5,27), polifarmasiyi etkileyen bağımsız faktörler olarak saptanmıştır.

Sonuç: Kardiyoloji polikliniğine başvuran hipertansiyon hastalarının \%54,4'ünde ( $\mathrm{n}=174)$ polifarmasi bulunmaktadır. Saptadığımız bu düzeyin literatürdeki benzer çalışma sonuçlarına göre genel olarak daha yüksek olduğu söylenebilir. Düşük eğitim seviyesi, komorbidite, uzun süredir HT nedeniyle takipli olmak polifarmasi için risk faktörleri olarak belirlenmiştir.
\end{abstract}

Anahtar Kelimeler: Polifarmasi, tedavi uyumu, hipertansiyon.

Sevinç Ö, Adalı MK, Til A, Kınacı Çimen Y. Pamukkale Üniversitesi Hastanesi Kardiyoloji Polikliniğine başvuran hipertansiyon hastalarında polifarmasi ve etkileyen faktörler. Pam Tıp Derg 2019;12:93-100.

\begin{abstract}
Purpose: Hypertension is considered to be an important public health problem in many developing countries where epidemiological transformation is the transition from infectious diseases to non-communicable diseases. The prevalence of hypertension is between $25 \%$ and $55 \%$. In addition, hypertension patients are among the risk groups of polypharmacy. Polypharmacy is considered to be an important health problem all over the world because it decreases patient compliance.

Material and method: This study was conducted with 320 hypertension patients. The questionnaire consisted of 21 questions. In addition, the treatment compliance was detected with the Drug Treatment Alert Scale. The evaluation of the data recorded in the questionnaire form pertaining to the individuals included in the research, was accomplished using Windows 17 program SPSS. In all the statistical analysis $p<0.05$ value was accepted "meaningful".
\end{abstract}

Özgür Sevinç, Doç.Dr. Pamukkale Üniversitesi Tıp Fakültesi, Halk Sağlığı Anabilim Dalı, DENizLí, e-posta: osevinc@pau.edu.tr (orcid. org/0000-0002-3231-8123)

Mehmet Koray Adalı, Uzm.Dr. Pamukkale Üniversitesi Tıp Fakültesi, Kardiyoloji Anabilim Dalı, DENiZLi, e-posta: korayadali@gamil.com (orcid. org/0000-0002-0054-6252)

Ayşen Til, Arş.Gör.Dr. Pamukkale Üniversitesi Tıp Fakültesi, Halk Sağlığı Anabilim Dalı, DENiZLí, draysentil@gmail.com(orcid.org/0000-00022283-1847) (Sorumlu yazar)

Yeşim Kınacı Çimen, Arş.Gör.Dr. Pamukkale Üniversitesi Tıp Fakültesi, Halk Sağlığı Anabilim Dalı, DENiZLI, e-posta: yeg13132@hotmail.com (orcid.org/0000-0002-7066-1299) 
Results: Of the participants, $153(47.8 \%)$ were female and $78.3 \%$ were married. The median age was 63 years. The rate of four or more medication usage per day was $54.4 \%$ and five or more medication usage per day was found as $44.4 \%$. There was a statistically significant difference between the participants' age, education status, coexisting chronic disease presence and duration of hypertension. Having a low education level, having an additional chronic disease and having long-term hypertension was determined as independent factors affecting polypharmacy.

Conclusion: We detected that polypharmacy exists in over more than half hypertension patients who applied to cardiology outpatient clinic. The risk factors identified for polypharmacy are low education level, comorbidity, and long follow-up due to hypertension.

Keywords: Polypharmacy, treatment compliance, hypertension.

Sevinç Ö, Adalı MK, Til A, Kınacı Çimen Y. Polypharmacy and affecting factors in hypertension patients who admitted Pamukkale University Hospital cardiology outpatient clinic. Pam Med J 2019;12:93-100.

\section{Giriş}

Tüm dünyada 18 yaş üstü bireylerin $\% 22,1^{\prime} i$ hipertansiyon hastasıdır. 1980 yılında 600 milyon kişi hipertansiyon hastası iken 2015 yılında 1,3 milyara ulaşmıştır. Yaşa göre hipertansiyon prevalansı değişiklik göstermekle birlikte erkeklerde $\% 24,1$ ve kadınlarda \%20 ,1 olarak bulunmuştur [1, 2]. Türkiye'de ise hipertansiyon prevalansı \%20,3 olarak bulunmuş olup kadınlarda \%20,1 ve erkeklerde $\% 20,3$ 'tür [2]. Tüm dünyada hipertansiyon toplam ölümlerin yaklaşık \%12,8'inden sorumludur ve toplamda 7,5 milyon insanın ölüm nedenini oluşturmaktadır [2]. Hipertansiyon prevalansının artması nüfus artışına, yaşlanma ve sağlıksız beslenme fiziksel aktivite kısıtııı̆ı gibi davranışsal risk faktörlerine bağlıdır [3].

Epidemiyolojik dönüşümün ile birlikte artan kronik hastalıklar çoklu ilaç kullanımlarını ve ilaç etkileşimlerini de beraberinde getirmektedir. Polifarmasi tanımı günümüzde net bir şekilde yapılamamakta olup 2004 'te DSÖ'nün yayınladığı kılavuza göre hastanın intiyacı olduğundan daha fazla ilaç kullanması olarak tanımlanmıştır [4]. Literatürde, kullanılan ilaç sayısına ve ilaç kullanım süresine göre farklı tanımlamalar görülmektedir. Bu tanımlamalardan bazılarında polifarmasi en az 240 gün süreyle 2 ve daha fazla ilaç kullanımı, 4 ve daha fazla ilaç kullanımı veya 5 ve daha fazla ilaç kullanımı olarak tanımlanmaktadır [5-7]. Polifarmasi prevalansı Dünya'da ve Türkiye'de $\% 11-\% 69$ arasında değişiklik göstermektedir [4, 8-13]. Hasta uyumunun azalmasına, ilaç-ilaç etkileşimine, yanlış ilaç kullanımına, istenmeyen ilaç yan etkilerine, acil servis başvurularında, hastaneye yatışlarda artışa neden olduğu için polifarmasi tüm dünyada önemli bir sağlık sorunu olarak değerlendirilmektedir [9, 14-16].
İleri yaş, huzur evinde kalma, hastada mevcut olan bilişsel sorunlar, görme bozuklukları, fonksiyonel bozukluklar ve eğitim düzeyindeki düşüklük gibi nedenlere ek olarak hipertansiyon vb. kronik hastalıklar da polifarmasiye yol açan faktörler olarak bilinmektedir [8, 9, 13]. Bununla birlikte antihipertansif ilaçların görülebilecek yan etkilerine karşı yeni bir ilaç reçete edilmesi de çoklu ilaç kullanımı için önemli bir risk faktörüdür $[13,16,17]$. Literatürde birinci ve ikinci basamak sağlık kurumuna başvuran hastalarda polifarmasi sıklığını tespit eden çalışmalar yer almaktadır. Ancak polifarmasi için risk faktörü olarak bilinen, tüm dünyada prevalansı giderek artan ve tedavisi için kombine ilaçların kullanılmasının gerektiği hipertansiyon hastalarında yapılan çalışma sayısı yetersizdir. Bu nedenle çalışmamızda polikliniğe başvuran hipertansiyon hastalarının çoklu ilaç kullanımları ve etkileyen faktörlerin tespit edilmesi amaçlanmıştır.

\section{Gereç ve yöntem}

Kesitsel tipteki araştırmamızın evrenini Ocak-Şubat 2018 tarihleri arasında Pamukkale Üniversitesi kardiyoloji polikliniğine başvuran hipertansiyon hastaları oluşturmaktadır. Evreni bilinmeyen örneklem genişliği formülüne göre güven aralığı \%95, hipertansiyon hastalarında polifarmasi prevalansı \%30 kabul edilerek minimum örneklem sayısı 323 kişi olarak belirlenmiştir. Çalışmaya, en az altı aydır hipertansiyon tedavisi gören, kognitif fonksiyonlarında bozukluk olmayan 45 yaş ve üzeri hastalar dâhil edilmiştir. Araştırmamızın bağımlı değişkeni polifarmasi olup, bağımsız değişkenleri; yaş, cinsiyet, en uzun yaşadığı yer, medeni durum, öğrenim durumu, sosyal güvence, alkol ve sigara kullanımı, hipertansiyon hastalık süresi, hipertansiyonda yaşam tarzı 
değişiklikleri, tedavi uyumu ve eşlik eden ek hastalık varlığıdır. Bağımlı değişkenimiz bu konuda yapılmış olan çalışmalar değerlendirilerek kategorize edilmiştir. Günlük 4 ve daha fazla ilaç kullanımı polifarmasi olarak kabul edilmiştir. Araştırmanın verileri literatür taranarak araştırmacılar tarafından oluşturulan anket formu ile toplanmıştır. Anket formu, hastanın sosyodemografik özelliklerini, hastalıklarını ve ilaç kullanımlarını sorgulayan 21 sorudan oluşmaktadır. Bununla birlikte tedavi uyumları Morisky Tedavi Uyum Ölçeği (MTUÖ-8) kullanılarak tespit edilmiştir. MTUÖ8 Tedaviye Uyum Ölçeği, 2003 yılında Morisky ve arkadaşları tarafından geliştirilmiştir ve sekiz ifadeyi kapsamaktadır. Puan arttıkça ilaç tedavisine uyum da artmaktadır. Bu puanlamaya göre 0-8 arası puan alınabilmektedir. Morisky puanı ; <6 olanlar kötü uyumlu, 6-7 olanlar orta uyumlu, 8 olanlar iyi uyumlu olarak sınıflandırılmıştır.

İstatiksel analizlerde SPSS 17 programı kullanılmıştır. Değişkenlerin normal dağııma uygunluğu Kolmogorov-Smirnow/ShapiroWilk testleri ile değerlendirilmiştir. Tanımlayıcı istatistiklerde sayı ve yüzdeler ile ortanca ve çeyrekler arası fark verilmiştir. Kategorik değişkenlerin karşılaştırılmasında ki-kare testi, polifarmasi ile ilişkili bağımsız faktörlerin belirlenmesinde lojistik regresyon analizi (backward) kullanılmış olup, tüm analizlerde $p<0,05$ anlamlı olarak kabul edilmiştir.

Pamukkale Üniversitesi Tıp Fakültesi Girişimsel Olmayan Etik Kurulu'ndan 09.01.2018 tarihinde 60116787-020/2490 sayılı karar ile etik kurul onayı alınmıştır. Hastalardan sözel olarak onamları alınmıştır.

\section{Bulgular}

Araştırmaya Pamukkale üniversitesi kardiyoloji polikliniğine başvuran hipertansiyon hastaları arasından 320 kişi $(\% 99,0)$ katılmıştır. Araştırmaya katılan kişilerin 153'ü $(\% 47,8)$ kadındır, 249'u $(\% 78,3)$ evlidir. Yaş ortancası 63 yıl olup, katılımcıların yaşları 41- 91 yıl aralığındadır. Katılımcıların en uzun yaşadığı yer \%38,9 $(n=124)$ il ve \%22,2 $(n=71)$ belde/ köy olarak bulunmuştur. Araştırmamıza en az okuma yazma bilmeyen $20(\% 6,3)$, en fazla ilkokul mezunu $126(\% 39,4)$ kişi katılmıştır. Katılımcılardan 6 kişi $(\% 1,9)$ herhangi bir sağlık güvencesine sahip değildir. Sırasıyla katılımcıların \%65,2 'si $(n=208)$ ve \%59,2'si $(n=187)$ yaşamları boyunca daha önce hiç alkol ve sigara tüketmemiştir. Araştırmaya katılanların sosyodemografik özellikleri Tablo 1 'de gösterilmiştir.

Çalışmamıza katılanların \%64,4'ü ( $n=206)$ 10 yıldan uzun süredir hipertansiyon hastasıdır ve \%50,0'sinin ek olarak en az bir kronik hastalığı vardır. Eşlik eden kronik hastalıkları arasında kardiyovasküler hastalıklar \%30,3 (n=97) ile ilk sırada yer almaktadır. Araştırmamıza katılan hipertansiyon hastalarından \%61,9'u $(n=198)$ diyet, \%72,2'si (n=231) tuz kısıtlaması, \%33,4'ü ( $n=107)$ düzenli egzersiz yapmaktadır. Günlük 4 ve daha fazla ilaç kullanım oranı tüm grupta $\% 54,4$ (65 yaş ve üzerinde $\% 65,4$ ), günlük 5 ve daha fazla ilaç kullanım oranı tüm grupta $\% 44,4$ (65 yaş ve üzerinde $\% 57,5$ ) olarak bulunmuştur. Katılımcıların \%49,5'inin $(n=141)$ tedaviye uyumu kötüdür. Katılımcıların hastalıkları ve tedavilerine ilişkin özellikleri Tablo 2'de gösterilmiştir.

Katılımcıların polifarmasi durumları (günlük 4 ve daha fazla ilaç kullanım); yaş dağılımları, cinsiyet, öğrenim durumu, sosyal güvence, riskli davranış varlığı, eşlik eden kronik hastalık varlığı ve tedavi uyumu değişkenlerine göre incelenmiştir (Tablo 3). Katılımcıların yaş, öğrenim durumu, eşlik eden kronik hastalık varlığı ve hipertansiyon hastalığı süresi değişkenlerine göre polifarmasi arasında istatistiksel olarak anlamlı fark saptanmıştır $(p<0,001)$. Ancak incelenen diğer değişkenlere göre polifarmasi arasında istatistiksel olarak anlamlı farklılık bulunmamıştır $(p>0,05)$. Günlük 4 ve daha fazla ilaç kullanımı ve ilişkili faktörler Tablo 3'de gösterilmiştir.

Polifarmasiyi etkileyen yaş, cinsiyet, öğrenim durumu, riskli davranış varlığı, ek kronik hastalık varlığı, hipertansiyon hastalık süresi, sigara kullanımı ve tedavi uyumu değişkenleri ile model oluşturulmuştur. Düşük eğitim seviyesi, ek kronik hastalığın olması ve uzun süredir hipertansiyon hastası olmak polifarmasiyi etkileyen bağımsız faktörler olarak saptanmıştır. Modelin açıklayıcılığı \%31,2'dir (Tablo 4).

\section{Tartışma}

Çalışmamızda 45 yaş ve üzeri hipertansiyon hastalarında polifarmasi sıklığının, günlük $\geq 4$ ilaç kullanımı için $\% 54,4$ ve günlük $\geq 5$ ilaç kullanımı için \%44,4 olduğu saptanmıştır. 
Tablo 1. Katılımcıların Genel Özellikleri

n (\%)

\begin{tabular}{|c|c|}
\hline \multicolumn{2}{|l|}{ Cinsiyet } \\
\hline Kadın & $153(47,8)$ \\
\hline Erkek & $167(52,2)$ \\
\hline \multicolumn{2}{|l|}{ En uzun yaşanmış yer } \\
\hline il & $124(38,9)$ \\
\hline İlçe & $124(38,9)$ \\
\hline Belde/Köy & $71(22,2)$ \\
\hline \multicolumn{2}{|l|}{ Medeni Durum } \\
\hline Bekar & $13(4,1)$ \\
\hline Evli & $249(78,3)$ \\
\hline Boşanmış/Dul/Ayrı yaşıyor & $56(17,6)$ \\
\hline \multicolumn{2}{|l|}{ Öğrenim durumu } \\
\hline Okuryazar değil & $20(6,3)$ \\
\hline Okuryazar & $38(11,8)$ \\
\hline İlkokul mezunu & $126(39,4)$ \\
\hline Ortaokul mezunu & $46(14,4)$ \\
\hline Lise mezunu & $52(16,3)$ \\
\hline Yüksekokul / Üniversite mezunu & $38(11,8)$ \\
\hline \multicolumn{2}{|l|}{ Sosyal güvence } \\
\hline SSK & $106(33,1)$ \\
\hline Bağ-kur & $100(31,3)$ \\
\hline Emekli sandığı & $86(26,8)$ \\
\hline Özel sigorta & $5(1,6)$ \\
\hline Yeşil kart & $17(5,3)$ \\
\hline Sağlık güvencesi olmayan & $6(1,9)$ \\
\hline \multicolumn{2}{|l|}{ Alkollü içecek tüketimi } \\
\hline Düzenli içici & $6(1,9)$ \\
\hline Sosyal içici & $44(13,8)$ \\
\hline Bırakmış & $61(19,1)$ \\
\hline Hiç içmemiş & $208(65,2)$ \\
\hline \multicolumn{2}{|l|}{ Sigara kullanımı } \\
\hline Aktif içici & $44(13,9)$ \\
\hline Bırakmış & $85(26,9)$ \\
\hline Hiç kullanmamış & $187(59,2)$ \\
\hline Yaş Ortanca \pm Çeyrekler arası fark & $63 \pm(41-91)$ \\
\hline Toplam & $320(100,0)$ \\
\hline
\end{tabular}


Tablo 2. Katılımcıların Hastalıklarına ve Tedavilerine İlişkin Özellikleri

\begin{tabular}{|c|c|}
\hline & n (\%) \\
\hline \multicolumn{2}{|l|}{ HT hastalık süresi } \\
\hline$\leq 10$ yıl & $114(35,6)$ \\
\hline 10 yıl üzeri & $206(64,4)$ \\
\hline \multicolumn{2}{|c|}{ Eşlik eden kronik hastalık } \\
\hline Var & $160(50,0)$ \\
\hline Yok & $160(50,0)$ \\
\hline \multicolumn{2}{|c|}{ Eşlik eden hastalıkların dağılımı } \\
\hline Kardiyovasküler hast. & $97(30,3)$ \\
\hline Endokrinolojik hast. & $81(25,3)$ \\
\hline Solunum sist. Hast. & $16(5,0)$ \\
\hline Romatolojik hast. & $11(3,4)$ \\
\hline Diğer & $13(4,0)$ \\
\hline \multicolumn{2}{|c|}{ HT da yaşam tarzı değişiklikleri } \\
\hline \multicolumn{2}{|c|}{ Diyet } \\
\hline Yapan & $198(61,9)$ \\
\hline Yapmayan & $122(38,1)$ \\
\hline \multicolumn{2}{|l|}{ Tuz kısıtlaması } \\
\hline Yapan & $231(72,2)$ \\
\hline Yapmayan & $89(27,8)$ \\
\hline \multicolumn{2}{|l|}{ Düzenli egzersiz } \\
\hline Yapan & $107(33,4)$ \\
\hline Yapmayan & $213(66,6)$ \\
\hline \multicolumn{2}{|l|}{ Tedavi uyumu } \\
\hline İyi & $65(22,8)$ \\
\hline Orta & $79(27,7)$ \\
\hline Kötü & $141(49,5)$ \\
\hline \multicolumn{2}{|c|}{ Günlük $\geq 4$ ilaç kullanımı (Polifarmasi) } \\
\hline Var & $174(54,4)$ \\
\hline Yok & $146(45,6)$ \\
\hline \multicolumn{2}{|c|}{ Günlük $\geq 5$ ilaç kullanımı (Polifarmasi) } \\
\hline Var & $142(44,4)$ \\
\hline Yok & $178(55,6)$ \\
\hline Toplam & $320(100,0)$ \\
\hline
\end{tabular}


Tablo 3. Günlük $\geq 4$ İlaç Kullanımı ( Polifarmasi) ile İlişkili Faktörler

\begin{tabular}{|c|c|c|c|}
\hline & $\begin{array}{c}\text { Günlük } \geq 4 \text { ilaç kullanan } \\
\text { (Polifarmasi) } \\
n(\%) \\
\end{array}$ & $\begin{array}{c}\text { Günlük < } 4 \text { ilaç kullanan } \\
n(\%)\end{array}$ & $p$ \\
\hline \multicolumn{4}{|l|}{ Yaş } \\
\hline 65 yaş altı & $85(45,7)$ & $101(54,3)$ & \multirow[t]{2}{*}{$<0,001$} \\
\hline 65 yaş ve üzeri & $87(65,4)$ & $46(34,6)$ & \\
\hline \multicolumn{4}{|l|}{ Cinsiyet } \\
\hline Kadın & $80(52,3)$ & $73(47,7)$ & \multirow[t]{2}{*}{0,616} \\
\hline Erkek & $92(55,1)$ & $75(44,9)$ & \\
\hline \multicolumn{4}{|l|}{ Öğrenim Durumu } \\
\hline Ortaokul ve altı & $139(60,4)$ & $91(39,6)$ & \multirow[t]{2}{*}{$<0,001$} \\
\hline Lise ve üzeri & $33(36,7)$ & $57(63,3)$ & \\
\hline \multicolumn{4}{|l|}{ Sosyal güvence } \\
\hline Var & $168(53,5)$ & $146(46,5)$ & \multirow[t]{2}{*}{0,820} \\
\hline Yok & $4(66,7)$ & $2(33,3)$ & \\
\hline \multicolumn{4}{|l|}{ Riskli davranış } \\
\hline Var & $173(55,1)$ & $141(44,9)$ & \multirow[t]{2}{*}{0,096} \\
\hline Yok & $1(16,7)$ & $5(83,3)$ & \\
\hline \multicolumn{4}{|c|}{ Eşlik eden kronik hastalık } \\
\hline Var & $119(74,4)$ & $41(25,6)$ & \multirow[t]{2}{*}{$<0,001$} \\
\hline Yok & $55(34.4)$ & $105(65,6)$ & \\
\hline \multicolumn{4}{|l|}{ Tedavi uyumu } \\
\hline İyi & $38(58,5)$ & $27(41,5)$ & \multirow{3}{*}{0,534} \\
\hline Orta & $47(59,5)$ & $32(40,5)$ & \\
\hline Kötü & $74(52,5)$ & $67(47,5)$ & \\
\hline \multicolumn{4}{|c|}{ HT hastalık süresi(yıl) } \\
\hline$\leq 10$ yll & $90(43,7)$ & $116(56,3)$ & \multirow[t]{2}{*}{$<0,001$} \\
\hline 10 yıl üzeri & $84(73,7)$ & $30(26,3)$ & \\
\hline
\end{tabular}

- Ki-kare testi

Tablo 4. Günlük $\geq 4$ İlaç Kullanımı ( Polifarmasi) ile İlişkili Faktörlerin Çoklu Analizi

\begin{tabular}{lccc}
\hline & OR & \%95 GA & $\boldsymbol{P}$ \\
\hline Düşük eğitim seviyesi & 5,670 & $3,260-9,861$ & $<0,001$ \\
Eşlik eden kronik hastalık varlığı & 2,026 & $1,112-3,690$ & $\mathbf{0 , 0 2 1}$ \\
Hipertansiyon hastalığının 10 yıl ve daha uzun süredir olması & 2,914 & $1,611-5,273$ & $<0,001$ \\
Adjusted $\mathbf{R}^{2}$ & 0,312 & & \\
\hline
\end{tabular}

- Backward Logistik Regresyon

Model; yaş, cinsiyet, öğrenim durumu, riskli davranış varlığı, ek kronik hastalık varlığı, hipertansiyon hastalık süresi, sigara kullanımı, tedavi uyumu

Saptadığımız bu düzeylerin literatürdeki benzer çalışma sonuçlarına göre genel olarak daha yüksek olduğu söylenebilir [1115, 17-19]. Bununla birlikte saptadığımız bu düzeylerden daha yüksek sonuçlar elde eden çalışmalar mevcuttur $[10,16]$. Literatürdeki çalışmalarla yaptığımız karşılaştırmada, çalışmaya katılanların alt yaş sınırları ve polifarmasi için kabul edilen ilaç sayısı kesme noktaları konularında farklılıklar bulunmaktadır
$[15,16,20]$. Bulgularımızı bu farklılıkları ortadan kaldıracak biçimde ele aldığımızda dahi bulduğumuz polifarmasi sıklığının diğer çalışmalara göre yüksek olduğu görülmektedir. Bu yüksekliğin temel nedeni çalışmamızın diğer çalışmalardan sonra yapılmış olması ve güncel durumu yansıtıyor olması olabilir. Polifarmasi sıklığının yıllar içinde artış gösterdiği [21, 22] göz önüne alındığında bu artışın doğal olduğu söylenebilir. Bununla birlikte çalışmamızın 
üçüncü basamak sağlık kuruluşunda yapılmış olmasına karşın diğer çalışmaların daha çok birinci basamak sağlık kuruluşlarına kayıttı kişiler veya ikinci basamak sağlık kuruluşlarına başvuranlar üzerinde yapılmış olması da bu farklılık üzerinde rol oynamış olabilir.

Çalışmamızda düşük eğitim seviyesi ile polifarmasinin ilişkili olduğu bulunmuştur. Eğitim seviyesi azaldıkça, kişilerin ilaçların doğru kullanımı, öz bakım ve hastalık yönetimi hakkında kararlar verebilmek gibi sağlık bilgilerini kavrama ve değerlendirme yetisinin yani sağlık okuryazarığının da azalması beklenen bir durumdur. Literatürde eğitim seviyesi ile polifarmasi arasında ilişki saptanmış çalışmalar mevcut olmasına karşın oldukça sınırlı sayıdadır [23, 24]. Bu durum, yurt içinde yapıımış olan çalışmalarda katıımcıların sosyodemografik özelliklerinin kısıtlı bir biçimde sorgulanması [12, 19] , yurt dışında yapılan çalışmalarda ise eğitim seviyesi ve sağlık okuryazarlığının toplumsal olarak yüksek olmasından kaynaklanıyor olabilir.

Araştırmamızda 10 yıl ve daha fazla süredir hipertansiyon hastası olanların polifarmasi sıklıkları daha yüksek bulunmuştur. Literatürde hipertansiyon hastalığının süresi ile polifarmasi ilişkisini sorgulayan çalışmalar sınırıdır $[18,20]$. Genel olarak çalışmalarda polifarmasi saptanan hastaların sahip oldukları hastalıklar arasında ilk üç sırada kardiyovasküler hastalıklar yer almaktadır [10, 13, 19]. Çalışmamızda komorbitenin polifarmasiyi arttırdığı bulunmuştur. Literatürdeki benzer çalışmalarda da komorbidite ile polifarmasi arasında pozitif ilişki saptanmıştır [13, 14, 17-19]. Polifarmasi konusunda yapılan çalışmalarda kullanılan günlük ilaç sayısının kesme noktaları olarak genellikle 4 ve üzeri ya da 5 ve üzeri sayıda ilaç kullanımının ele alındığı görülmüştür. Ancak polifarmasi, intiyaçtan fazla ya da gereksiz ilaç kullanımı olarak tanımlanmaktadır $[4,25]$ ve bu tanım göz önüne alındığında ilaç sayısı için kesme noktalarının kişilerin komorbidite durumlarınagöre değişebileceğianlaşımaktadır.

Çalışmamıza katılan hastaların yarısı hipertansiyon dışında en az bir kronik hastalığa sahip ve eşlik eden hastalıklarının tedavisi için ilaç kullanmaktadır. Bu hastaların kullandıkları ilaçları ve hastalıklarının tedavisindeki önemi sorgulanmamıştır. Dolayısıyla bu durum çalışmamızın sınırıııklarından birisi olarak kabul edilebilir. Çalışmamızın bir diğer sınırlığı ise hipertansiyon hastalarının tek bir hastaneden ve başvuranlar arasından seçilmiş olmasıdır. Bununla birlikte son yıllarda hızla artan sıklığı ve yol açtığı pek çok sağlık sorunuyla tüm dünyada halk sağlığı sorunu haline gelen hipertansiyon ile polifarmasi ilişkisinin tespit edilmesi ve bu konuda çalışma sayısının yetersiz sayıda olması çalışmamızın önemini artıırmaktadır.

Sonuç olarak çalışmamızda 45 yaş ve üzeri hipertansiyon hastalarında polifarmasi sıklığının, günlük $\geq 4$ ilaç kullanımı için $\% 54,4$ ve günlük $\geq 5$ ilaç kullanımı için $\% 44,4$ olduğu saptanmıştır. Saptadığımız bu düzeylerin literatürdeki benzer çalışma sonuçlarına göre genel olarak daha yüksek olduğu söylenebilir. Düşük eğitim seviyesi, komorbidite, uzun süredir HT nedeniyle takipli olmak polifarmasi için bağımsız risk faktörleri olarak belirlenmiştir.

Çalışma bulgularımızın ışığında sağlık açısından bir risk, ekonomik açıdan da bir yük olarak değerlendirilebilecek polifarmasinin ortadan kaldırılabilmesi için başta hipertansiyon hastaları olmak üzere tüm toplumda akılcı ilaç kullanımı konusunda ve sağlık okuryazarlığını geliştirici nitelikte sağlık eğitimlerinin gerekli olduğunu öne sürmekteyiz. Hipertansiyon hastalarında bu eğitimin hastalığın erken dönemde yapılması ilerleyen dönemde polifarmasi yönünden bir artışı önleyebilir. Bununla birlikte söz konusu eğitimin etkin bir biçimde yapılandırılabilmesi için farklı eğitim programlarının etkinliğini ölçecek olan müdahale çalışmaları bu konuda yol gösterici olacaktır.

Çıkar İlişkisi: Yazarlar çıkar ilişkisi olmadığını beyan eder.

\section{Kaynaklar}

1. Whelton PK, Carey MR, Aronow WS, et al. ACC/ AHA/ AAPA/ ABC/ ACPM/ AGS/ APhA/ ASH/ASPC/ NMA/PCNA Guideline for the Prevention, Detection, Evaluation, and Management of High Blood Pressure in Adults: A Report of the American College of Cardiology/ American Heart Association Task Force on Clinical Practice Guidelines. J Am Coll Cardiol 2018;71:127248.

2. WHO Global Health Observatory data repository. Avaliable at: http://apps.who.int/gho/data/view. main.2464ESTSTANDARD?lang=en Erişim tarihi: 10 Mart 2018.(Accessed March 10, 2018). 
3. Priority Medicines for Europe and the World. Warren Kaplan, Richard Laing. World Health Organization Department of Essential Drugs and Medicine Policy. November 2004. Avaliable at:http://apps.who.int/ iris/bitstream/handle/10665/68769/WHO_EDM_ PAR_2004.7.pdf Erişim tarihi: 10 Mart 2018.(Accessed March 10, 2018).

4. Veehof L, Stewart R, Haaijer-Ruskamp F, Jong BM. The development of polypharmacy. A longitudinal study. Fam Pract 2000;17:261-267.

5. United Kingdom Department of Health. Medicines and older people: implementing medicines-related aspects of the The National Service of Framework (NSF) for older people. 2001. Available at:http://webarchive. nationalarchives.gov.uk/20130107105354/http/www. dh.gov.uk en/Publicationsandstatistics/Publications/ PublicationsPolicyAndGuidance/DH_4008020. Erişim tarihi: 10 Mart 2018.(Accessed March 10, 2018).

6. Fillit $\mathrm{HM}$, Futterman $\mathrm{R}$, Orland $\mathrm{BI}$, et al. Polypharmacy management in Medicare managed care: changes in prescribing by primary care physicians resulting from a program promoting medication reviews. Am J Manag Care 1999;5:587-594

7. Rochon PA, Schmader KE, Daniel JS. Drug prescribing for older adults (2012). Available at: http://pl.imul.pl/ sites/default/files/Drug\%20prescribing $\% 20$ for $\% 20$ older\%20adults\%20-\%20UpToDate.pdf. Erişim tarihi: 10 Mart 2018.(Accessed March 10, 2018).

8. Yıldırım AB, Kılınç AY. Polypharmacy and drug interactions in elderly patiens. Türk Kardiyol Dern Ars 2017;45:17-21.

9. Taşkın Şayir Ç, Evcik Toprak D, Aslan Karaoğlu S. Evaluation of polypharmacy and complementary therapy use in patients $\geq 65$ years, attending to family medicine outpatient Clinic of Şişli Etfal Training and Research Hospital. Turkish Journal of Family Practice 2014;18:35-41.

10. Qato DM, Alexander GC, Conti RM, Johnson M, Schumm $\mathrm{P}$, Lindau ST. Use of prescription and over-the-counter medications and dietary supplements among older adults in the United States. JAMA 2008;300:28672878.

11. Gökçe Kutsal Y. Yaşlılarda çoklu ilaç kullanımı (Polypharmacy in elderly). Turk J Geriatr 2006;Özel Sayı:37-44.

12. Arslan Ş, Atalay A, Gökçe Kutsal Y. Yaşlılarda ilaç tüketimi. Turk J Geriatr 2000;3:56-60.

13. Kojima T, Akishita M, Nakamura T, Nomura K, Ogawa S, lijima K, Eto M, Ouchi Y. Association of polypharmacy with fall risk among geriatric outpatients. Geriatr Gerontol Int 2011;11:438-444.

14. Nobili A, Licata G, Salerno F, et al. SIMI Investigators. Polypharmacy, length of hospital stay, and in-hospital mortality among elderly patients in internal medicine wards. The REPOSI study. Eur J Clin Pharmacol 2011;67:507-519.
15. Ramage-Morin PL. Medication use among senior Canadians. Health Rep 2009;20:37-44.

16. Morin $L$, Vetrano $D L$, Rizzuto $D$, Calderón-Larrañaga A, Fastbom J, Johnell K. Choosing Wisely? Measuring the burden of medications in older adultsnear the end of life: nationwide, longitudinal cohort study. Am J Med 2017; 130:927-936.

17. Çakmur H. Türkiye'nin iki farklı ilinde (Kars-İzmir) yaşlılarda polifarmasiyi etkileyen faktörler. Turkiye Klinikleri J Med Sci 2014;34:71-80.

18. Yaylacı S, Aydın E, Ösken A, ark. İç hastalıkları polikliniğine başvuru nedenleri, kronik hastalıklar ve polifarmasi oranları. Ortadoğu Tıp Derg 2016;8:31-35.

19. Öztürk Z, Uğraş GK. Yaşlı hastalarda ilaç kullanımı ve polifarmasi. Tepecik Eğit. ve Araşt. Hast. Derg 2017;27:103-108.

20. Bertrand N. Mukete, Keith CF. Polypharmacy in older adults with hypertension: a comprehensive review. The J Clin Hypertens (Greenwich) 2016;18:10-18.

21. Linjakumpu T, Hartikainen S, Klaukka T, Veijola J, ,Kivelä $\mathrm{S}$, Isoaho R. Use of medications and polypharmacy are increasing among the elderly. J Clin Epidemiol 2002;55:809-817.

22. Sheikh A, Dhingra-Kumar N, Kelley E, Kieny MP, Donaldson LJ. The third global patient safety challenge: tackling medication-related harm. Bull World Health Organ 2017; 95:546.

23. Haider SI, Johnell K, Weitoft GR, Thorslund M, Fastbom $J$. The influence of educational level on polypharmacy and inappropriate rrug use: A register-based study of more than 600,000 older people. J Am Geriatr Soc 2009;57:62-69.

24. Golchini N, Frank SH, Vince A, Isham L, Meropol SB. Polypharmacy in the elderly. J Res Pharm Pract 2015;4:85-88.

25. Jokanovic N, Tan EC, Dooley MJ, Kirkpatrick CM, Bell JS. Prevalence and factors associated with polypharmacy in long-term care facilities: a systematic review. J Am Med Dir Assoc 2015;16:1-12. 